\title{
Association of quarter milking measurements and cow-level factors in an automatic milking system
}

\author{
J. F. Penry, ${ }^{* 1}$ P. M. Crump, ${ }^{*}$ L. L. Hernandez, ${ }^{*}$ and D. J. Reinemann† \\ *Department of Dairy Science, and \\ †Department of Biological Systems Engineering, University of Wisconsin-Madison, Madison 53706
}

\begin{abstract}
The primary aim of this observational study, in a single herd milked using multiple automatic milking system units, was to describe associations of quarter milk yield variability and quarter peak milk flow rate with cow-level factors. Information from the current lactation of 1,549 primiparous and multiparous cows was collected from January to December 2015. Data from each individual milking used in the analysis included quarter milk yield (QMY), udder milk yield, quarter peak milk flow rate (QPMF), quarter average milk flow rate (QAMF), quarter milking time, and milking interval. Milking interval and milk yield were used to calculate milk production rate $(\mathrm{kg} / \mathrm{h})$ at the quarter and udder levels. We investigated associations between QPMF and milking interval, QPMF and days in milk, and QMY and QAMF. A strong association between QPMF and both QAMF and milking interval was observed. A moderate association was found between QPMF and stage of lactation. However, QMY was not a useful indicator of QPMF because of the weak association observed between these variables. In this study, rear quarter QPMF was significantly increased by $3 \%$ compared with front quarter QPMF (1.45 vs $1.41 \mathrm{~kg} /$ min). Quarter milk yield was calculated as a percentage contribution of total udder milk yield per 10-d in milk window and ranked from lowest to highest contribution. Quarter contribution to udder milk yield showed a high level of variability, with $39 \%$ of animals having all 4 quarters change contribution rank at least once during part of or the whole lactation. Only $14 \%$ of cows were observed to have no change in quarter rank. When quarter contribution was assessed, irrespective of physical position of quarter within the udder, the percent of highest to lowest contribution across the lactation was relatively stable. The standard deviation of quarter
\end{abstract}

Received November 18, 2017.

Accepted March 21, 2018.

${ }^{1}$ Corresponding author: penry@wisc.edu milk production rate for each cow was regressed against the same cow's peak udder milk production rate, within a lactation, to ascertain whether quarter milk production rate variance could be used to predict peak udder milk production rate. Knowledge of the intra-udder quarter milk production rate standard deviation for an individual cow is not useful in predicting peak udder milk production rate. Quarter milking time appears to be a useful indicator to predict the optimal order of teatcup attachment. Analysis from this large, singleherd population indicates that QPMF is associated with the cow-level factors milking interval and days in milk, and that intra-udder QMY is highly variable.

Key words: automatic milking system, milking interval, milk production rate

\section{INTRODUCTION}

The introduction of automatic milking systems (AMS) in the early 1990s has facilitated a focus toward milking performance of individual quarters compared with performance solely at the cow level. Milking parameters that are routinely measured at the quarter level in each milking in AMS include milk yield (QMY), average milk flow rate (QAMF), and peak milk flow rate (QPMF). Milk synthesis is largely regulated at the local level of the quarter (Wall and McFadden, 2012; Weaver and Hernandez, 2016); hence, differences between QMY are of potential interest. Despite the ability to explore milk yield at the quarter level, much of the research into optimization of AMS has used udder milk yield as the production variable (de Koning and Ouweltjes, 2000; Hogeveen et al., 2001; André et al., 2010).

Very few researchers have explored variation in QMY in either commercial AMS installations or research herds with quarter milking capability. The repeatability of QMY has been reported to be high (Rothenanger et al., 1995). To quantify variation in QMY between quarters, intra-udder, only the coefficient of variation $(\mathbf{C V})$ has been reported in the literature. Forsbäck et al. (2010) reported within-cow, quarter-level CV of $7 \%$ 
in a small Swedish research herd, whereas Fogsgaard et al. (2015) used CV to quantify the degree of variability in QMY following clinical mastitis cases in 2 commercial herds. In that observational study, they observed a within-cow, quarter-level CV of approximately 19 to $23 \%$ in the control group.

Optimization of any AMS installation is primarily concerned with the maximum milk yield per AMS in a defined period (Sonck and Donkers, 1995). Findings from an observational study of 635 North American herds using AMS indicated that an increase in cow milk yield was associated with increased milkings and total box time/day, in addition to increased milk flow rate (Tremblay et al., 2016). No difference was observed between front and rear QPMF in one Dutch study (Tancin et al., 2003), which differed from increased QPMF observed in rear quarters in 2 other studies (Rothschild et al., 1980; Wellnitz et al., 1999). Quarter milk yield was not found to be associated with QPMF when QPMF was categorized into low, medium, and high milkability (Tancin et al., 2006).

A better understanding of cow-level factors influencing QPMF under constant milking machine settings, in addition to a clearer description of intra-udder QMY variability, could assist in executing more optimal milking management strategies where milk is harvested at the quarter level, such as with AMS. The primary aim of this observational study was to describe QMY variability and QPMF associations with cow-level factors in a large commercial herd using multiple AMS. The secondary aim was to describe relationships between other milk harvesting indicators to support the primary aim.

\section{MATERIALS AND METHODS}

This observational study was conducted on a 1,549cow (Holstein Friesians) commercial dairy farm located in the northeastern United States using 20 AMS units (De Laval VMS, DeLaval, Tumba, Sweden). Cows in the study herd had an average daily milk yield of $34.6 \mathrm{~kg}$ and 2.3 average lactations, and were housed in freestalls on sand bedding. The feed base was a partial mixed ration supplemented with approximately $3 \mathrm{~kg}$ of concentrate feed/cow per day. Concentrate feeding was not adjusted according to individual cow production levels. Each AMS serviced a pen of 55 cows, with 6 pens of primiparous cows (L1) and 14 pens of multiparous cows $(\mathbf{L} \mathbf{2}+)$. The number of animals per AMS was within the stocking rate range of 50 to 70 cows/ AMS reported by Hallen Sandgren and Emanuelson (2017) but lower than the average because of management decisions emphasizing cow comfort and access to feeding areas to improve daily milk yield. As animals freshened, they were allocated to evenly distribute cow DIM between pens. Fewer than $10 \%$ of the animals were moved to different pens in a 12 -mo period. Milking permission was granted to L1 cows if they had not been successfully milked in the previous $5 \mathrm{~h}$, whereas milking permission was granted to L $2+$ cows if they had not been successfully milked in the previous $6 \mathrm{~h}$. No milk production parameters were used to determine milking permission. Milking configuration of the AMS (system vacuum and pulsation settings) was not altered during the study period. Teatcup removal was based on a threshold of $0.2 \mathrm{~kg} / \mathrm{min}$ applied at the quarter level. Under normal farm protocol, cows were only fetched if they had not recorded a successful milking within $24 \mathrm{~h}$ of the previous milking. Within an individual pen, cow flow between the freestall area, AMS, and feedbunk was via a guided or semi-guided traffic system. All 20 pens were of consistent design and size, with the exception of gate location for the guided or semi-guided traffic system.

\section{Observational Data Study Base}

Cow identification, milking start time (date, hour, minute, second), time in the AMS (minute, second), and QMY $(\mathrm{kg})$, QAMF ( $\mathrm{kg} / \mathrm{min})$, QPMF $(\mathrm{kg} / \mathrm{min})$ and incomplete milkings were recorded for each cow milking (Delpro, DeLaval). Quarter average milk flow rate was calculated as QMY/total quarter teatcup attachment time, and QPMF was defined as the maximum milk flow rate during any individual quarter milking. An incomplete milking was defined as a quarter milking where the teat was not located by the AMS, or the recorded QMY was less than 50\% of expected QMY. An incomplete milking was not identified by the AMS when QMY was $>3 \mathrm{~kg}$ or when expected QMY was $<1$ $\mathrm{kg}$. Data were grouped by lactation number (1-6) or by 10-d DIM window. All milking records from January through December 2015 were collected. Data were only eligible for analysis if the following criteria were met: (1) data were from an individual cow's most recent lactation in 2015 if she recorded parts of 2 lactations in that calendar year; (2) an individual milking had no record of any quarter having an incomplete milking, typically resulting in little or no milk yield and milk flow; (3) udder milk yield was within the range from 1 to $70 \mathrm{~kg}$, QMY was within the range from 0.1 to 15 $\mathrm{kg}$, and QAMF or QPMF was greater than $0.1 \mathrm{~kg} / \mathrm{min}$; (4) the milking interval (MI), based on elapsed time between 2 milking events, was not greater than $48 \mathrm{~h}$. Eligibility criterion (3) was to remove milk yield and milk flow rate values from analysis that were deemed biologically implausible based on herd milk recording history and typical MI. Eligibility criterion (4) was set 
at $48 \mathrm{~h}$ to make allowance for the cow fetching criteria applied by farm staff as previously described. Criteria for implausible milk production rate (MPR) results are described in the Statistical Analysis section. An additional data processing step involved removing from analysis all milking records from any cow diagnosed with clinical mastitis $(\mathrm{n}=154)$ from $14 \mathrm{~d}$ before the diagnosis date.

During calendar year 2015, 1,104,570 milking records were available for analysis, with $34.2 \%$ of available records removed because of multiple lactations; $11.8 \%$ removed because of incomplete milkings, $0.02 \%$ removed due to biologically implausible milk flow rate, milk production, or MPR results; and $0.4 \%$ removed due to a clinical mastitis treatment. All percentages describe the extent of data removal from the available records. The resulting study base for observational data analysis contained 593,003 individual cow milking records that met all eligibility criteria for analysis.

\section{Statistical Analysis}

All data manipulation and statistical analysis was performed in SAS software (version 9.4; SAS Institute Inc., Cary, NC). Quarter milking time (QMT) was calculated for each quarter as QMY/QAMF (min). Udder milk yield for each milking was calculated by summing all QMY. Udder AMF (UAMF) was approximated by summing all QAMF, with the same approach used to estimate udder PMF (UPMF). The estimates calculated for both UAMF and UPMF, although calculated using the same method for all recorded milkings, are approximate because cup attachment typically occurs over 30 to $40 \mathrm{~s}$ and teatcup detachment occurs is at different times in AMS. Hence, the calculated UAMF will not be as accurate as that recorded in a conventional milking system. Additionally, individual quarters may not reach QPMF at the same time. Udder milk production rate (UMPR) was calculated for each milking by dividing udder milk yield by MI with this UMPR $(\mathrm{kg} / \mathrm{h})$ applying to the inter-milking period immediately before that milking. Quarter MPR (QMPR) was calculated using the same approach but with QMY in place of udder milk yield. Hence, each milking event had $1 \mathrm{MI}$ and $5 \mathrm{MPR}$ records (udder and 4 quarters). Separate eligibility criteria were applied to MPR records. Cows recording an UMPR of greater than 2.7 $\mathrm{kg} / \mathrm{h}$ or a QMPR of greater than $1.4 \mathrm{~kg} / \mathrm{h}$ had that MPR record removed from analysis. These criteria were used to remove data that were considered biologically implausible. All data used in analyses were assessed for normality.

Mean, variance, and SD values for AMF, QAMF, PMF, QPMF, UMPR, QMPR, and MI were calculated by cow and 10-d DIM window or by 10-d DIM window only using the SAS MEANS procedure. These mean values for flow rate were the basis for the majority of analyses. The mean values for quarter milk yield were used to calculate a percentage contribution to udder milk yield for each cow within an individual 10-d DIM window. The SAS REG procedure was used to perform all linear regressions. After initial linear regression analysis, studentized residual values greater than 4 for QAMF and QPMF were removed from final linear regressions reported. Linear regressions of mean QPMF versus mean QMY were performed within individual 10-d DIM windows to control for the potential confounder of lactation curve changes to QMY. The SAS RANK procedure was used to rank quarter percentage contribution to mean udder milk yield by cow and 10-d DIM window. Within this procedure, the quarter with the highest percentage contribution was rank 4 and the lowest percentage contribution was rank 1 . Variance of rank was calculated for each cow's 10-d DIM window available for analysis. These variance data were then used to count the number of quarters that changed rank at least once for each cow for DIM 10 to 300, or DIM where records were available within 10 to 300 . Regarding the change in rank calculation, individual milking QMY was rounded to the nearest $0.9 \mathrm{~kg}$, which was based on the mean, per milking, quarter milk yield SD. Hence, $0.9 \mathrm{~kg}$ was the yield threshold required for a quarter to have changed rank, based on changes recorded for an individual milking in any 10-d DIM window.

The SAS RANK procedure was also used to rank quarter by mean 10-d window QMT within cow: within a 10-d DIM window, each cow's quarters were ranked from longest to shortest QMT. The AMS teatcup attachment order is fixed so cows were identified if their teatcup attachment order was longest QMT quarter attached first through to shortest QMT quarter attached last (optimal attachment group), or if their teatcup attachment order was opposite of this: shortest QMT quarter attached first through to longest QMT quarter attached last (sub-optimal attachment group). Each group was analyzed for udder milk yield regressed against time in the AMS.

The SAS MIXED procedure was used to create and determine significance of least squares means (LSM) for dependent variables QMY, QAMF, and QPMF. The model was y $=$ quarter (fixed) and cow (random). Observations were weighted according to frequency (Table 1). The SAS MIXED procedure was also used to create and determine significance of LSM for dependent variable MI. The model was MI = DIM window (fixed) and cow (random). Observations were weighted according to frequency (Table 2). 
Table 1. Descriptive statistics of least squares means $( \pm \mathrm{SEM})$ for quarter milk yield (QMY), quarter average milk flow rate (QAMF), and quarter peak milk flow rate (QPMF) for DIM 10 to $300^{1}$

\begin{tabular}{lccc}
\hline Quarter & QMY $(\mathrm{kg})$ & QAMF $(\mathrm{kg} / \mathrm{min})$ & QPMF $(\mathrm{kg} / \mathrm{min})$ \\
\hline Left front & $2.84^{\mathrm{a}} \pm 0.002$ & $0.97^{\mathrm{a}} \pm 0.0004$ & $1.42^{\mathrm{a}} \pm 0.0005$ \\
Right front & $2.86^{\mathrm{a}} \pm 0.002$ & $0.96^{\mathrm{a}} \pm 0.0004$ & $1.41^{\mathrm{a}} \pm 0.0005$ \\
Left rear & $3.54^{\mathrm{b}} \pm 0.002$ & $0.99^{\mathrm{b}} \pm 0.0004$ & $1.45^{\mathrm{b}} \pm 0.0005$ \\
Right rear & $3.55^{\mathrm{b}} \pm 0.002$ & $1.00^{\mathrm{b}} \pm 0.0004$ & $1.46^{\mathrm{b}} \pm 0.0005$
\end{tabular}

${ }^{\mathrm{a}, \mathrm{b}}$ Means within a column with different superscripts differ at $P<0.05$. ${ }^{1}$ Observations: $\mathrm{n}=1,517$ for all quarters; all lactation numbers are included.

The SAS GLM procedure was used to determine whether the linear and quadratic coefficients for the model were different across quarters. The GLM model was $\mathrm{QPMF}=$ quarter $+\mathrm{MI}+($ quarter $\times \mathrm{MI})+($ quarter $\left.\times \mathrm{MI}^{2}\right)($ Table 3$)$. The SAS GLM procedure was used to determine whether the linear coefficients for the model were different across quarters. The GLM model was $\mathrm{QPMF}=$ quarter $+\mathrm{DIM}+($ quarter $\times$ DIM $)$ (Table 4). The SAS GLM procedure was also used to determine whether the linear coefficients for the model were different. The GLM model was QPMF $=$ quarter $+\mathrm{QAMF}+($ quarter $\times \mathrm{QAMF})($ Table 5$)$.

\section{RESULTS}

Mean QMY was significantly greater in rear quarters compared with front quarters by approximately $25 \%$. A significant 3\% difference in mean QAMF and mean QPMF between quarters was also observed (Table 1), with rear quarters having a greater value for both measures. The CV for QMY ranged from 35 to $42 \%$. During DIM 1 to 300, there was a significant change in QPMF of $6 \%$ across 10-d DIM windows from the minimum to maximum PMF (1.38 to $1.46 \mathrm{~kg} / \mathrm{min}$ ) and a significant increase from front to rear quarter PMF (1.41 to 1.45 $\mathrm{kg} / \mathrm{min}$ ). The mean MI for this herd across DIM 10 to 300, which approximates a standard lactation length, was $8.37 \mathrm{~h}$. When DIM was grouped in $90-$ or $100-\mathrm{d}$ blocks, there was no significant change in mean MI for L1 cows from DIM 10 to 300 (Table 2). However, L2+ cows demonstrated a significant increase in MI of 1.1

Table 2. Summary data for least squares means $( \pm$ SEM $)$ of milking interval for L1 (primiparous) and L2+ (multiparous) cows

\begin{tabular}{lcc}
\hline & \multicolumn{2}{c}{ Mean milking interval $(\mathrm{h})$} \\
\cline { 2 - 3 } DIM window & L1 animals & L2+ animals \\
\hline 10 to 100 & $7.87^{\mathrm{a}} \pm 0.07$ & $8.71^{\mathrm{b}} \pm 0.06$ \\
101 to 200 & $7.90^{\mathrm{a}} \pm 0.08$ & $9.26^{\mathrm{c}} \pm 0.06$ \\
201 to 300 & $7.75^{\mathrm{a}} \pm 0.09$ & $9.78^{\mathrm{d}} \pm 0.06$ \\
\hline
\end{tabular}

${ }^{\mathrm{a}-\mathrm{d}}$ Means within a column with different superscripts differ at $P<$ 0.05 .
Table 3. Regression results $( \pm \mathrm{SE})$ for quarter peak milk flow rate $(\mathrm{kg} / \mathrm{min})$ versus milking interval $(\mathrm{MI} ; \mathrm{h})$ and $\mathrm{MI}^{2}$ for DIM 10 to 100 (all lactation numbers included)

\begin{tabular}{lccc}
\hline & \multicolumn{2}{c}{ Regression slope coefficient } & \\
\cline { 2 - 3 } Quarter & $\mathrm{MI}$ & $\mathrm{MI}^{2}$ & $\mathrm{R}^{2}$ \\
\hline Left front & $0.055^{\mathrm{a}} \pm 0.004$ & $0.00170^{\mathrm{a}} \pm 0.0002$ & 0.98 \\
Right front & $0.056^{\mathrm{a}} \pm 0.004$ & $0.00170^{\mathrm{a}} \pm 0.0002$ & 0.99 \\
Left rear & $0.057^{\mathrm{a}} \pm 0.004$ & $0.00165^{\mathrm{b}} \pm 0.0002$ & 0.97 \\
Right rear & $0.051^{\mathrm{a}} \pm 0.004$ & $0.00130^{\mathrm{c}} \pm 0.0002$ & 0.99 \\
\hline
\end{tabular}

$\overline{{ }^{a-c} \text { Means within a column with different superscripts differ at } P<}$ 0.05 .

h from DIM 10-100 to DIM 201-300. An example plot and associated regressions with linear and quadratic coefficients for mean QPMF versus MI (rounded to nearest hour) is presented in Figure 1 (left front quarter, DIM 10 to 100) and Table 3. The curvilinear line of best fit for this regression indicated that the rate of increase in PMF slowed after an MI of 11 to $12 \mathrm{~h}$. The linear slope coefficient between quarters did not differ but we detected a significant difference between front and rear quarters and between rear quarters for the quadratic coefficient $(P<0.001)$. The $\mathrm{R}^{2}$ for all regressions was high $(\geq 0.97)$. A plot describing the relationship between QPMF and DIM in the left front quarter indicated that mean QPMF trended downward with increasing DIM, although the magnitude of change was small at approximately $7 \%$ between DIM 10 and 300 (Figure 2). The plot shape for all quarters was the same general form, so only results for the left front quarter are shown. Because of the sigmoid-like shape of the plotted points, 3 linear regressions were performed (DIM 10 to 50, DIM 51 to 150, DIM 151 to 300$)$. The results indicated a negative association between QPMF and DIM from DIM 10 to 50, a positive association from DIM 51 to 150 , and a negative

Table 4. Linear regression slope coefficients and $\mathrm{R}^{2}$ estimates for quarter peak milk flow rate $(\mathrm{kg} / \mathrm{min}$ ) versus DIM window (all lactation numbers included)

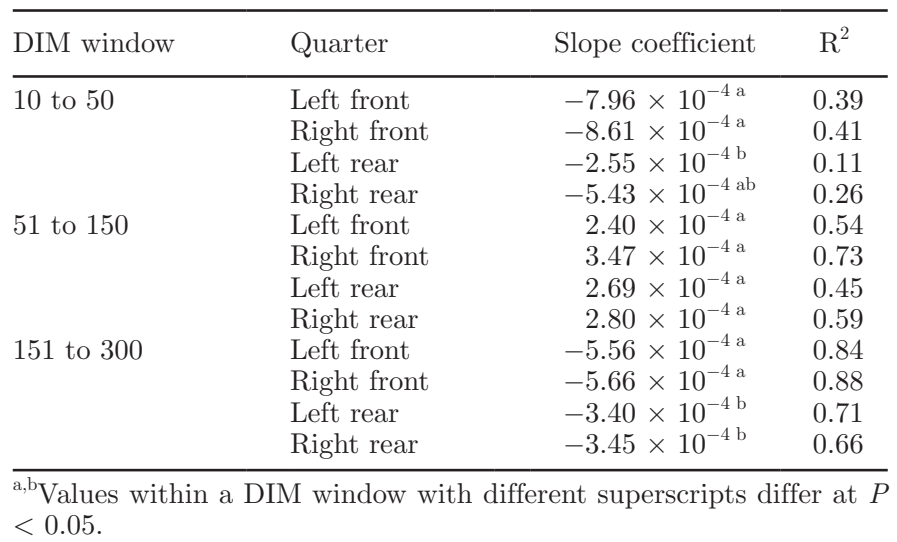


Table 5. Linear regression results $( \pm \mathrm{SE})$ for quarter peak milk flow rate $(\mathrm{kg} / \mathrm{min})$ versus quarter average milk flow rate $(\mathrm{kg} / \mathrm{min})$ for DIM 10 to 100 (all lactation numbers included)

\begin{tabular}{lcc}
\hline Quarter & $\begin{array}{c}\text { Regression slope } \\
\text { coefficient }\end{array}$ & $\mathrm{R}^{2}$ \\
\hline Left front & $1.195^{\mathrm{a}} \pm 0.003$ & 0.90 \\
Right front & $1.198^{\mathrm{a}} \pm 0.003$ & 0.90 \\
Left rear & $1.154^{\mathrm{b}} \pm 0.003$ & 0.92 \\
Right rear & $1.154^{\mathrm{b}} \pm 0.003$ & 0.92 \\
\hline
\end{tabular}

a,b Values with different superscripts differ at $P<0.05$.

association again from DIM 151 to 300 (Table 4). The $\mathrm{R}^{2}$ for all regressions was increased in the latter 2 DIM periods compared with the first.

Linear regression of the association between the left front QPMF and QAMF from DIM 10 to 100, is shown in Figure 3. Table 5 describes the slope coefficients for all quarters QPMF versus QAMF, with no significant difference detected between the coefficients for both front quarters and the same nonsignificant result when rear quarter coefficients were compared. However, when quarters were grouped together, we detected a significant increase in slope coefficients when front quarters were compared with rear quarters $(P<0.001)$. In all cases, the linear regression slope coefficient was positive and the $\mathrm{R}^{2}$ was $\geq 0.90$. Eliminating data points with a studentized residual $>4$ before the production of all final linear regressions for this association removed $0.3 \%$ of the data. This process was undertaken to remove outlier data. An example (left front quarter) of the association between per cow mean QPMF and mean QMY for DIM window 50 to 60 is shown in Figure 4. Linear regression output for this association in all 4 quarters and 5 selected DIM windows (50 to 60, 100 to 110,150 to 160,200 to 210 , and 250 to 260 ) demonstrated a mean regression coefficient of $1.198 \pm 0.054$ and a mean $\mathrm{R}^{2}$ of $0.17 \pm 0.009$. The low mean $\mathrm{R}^{2}$ for all 20 regressions indicates that less than $20 \%$ of any association between these 2 variables was described by the regression equation.

Relative to QMT, when teatcup attachment order was considered suboptimal (shortest QMT quarter attached first to longest QMT quarter attached last), the rate of udder milk yield per minute of AMS time was approximately $58 \%$ less compared with cows in the optimal attachment order group (longest QMT quarter attached first to shortest QMT quarter milked last).

The per cow and per 10-d DIM window percentage quarter contribution to mean udder milk yield for all windows from DIM 10 to 300 is presented in Figure 5

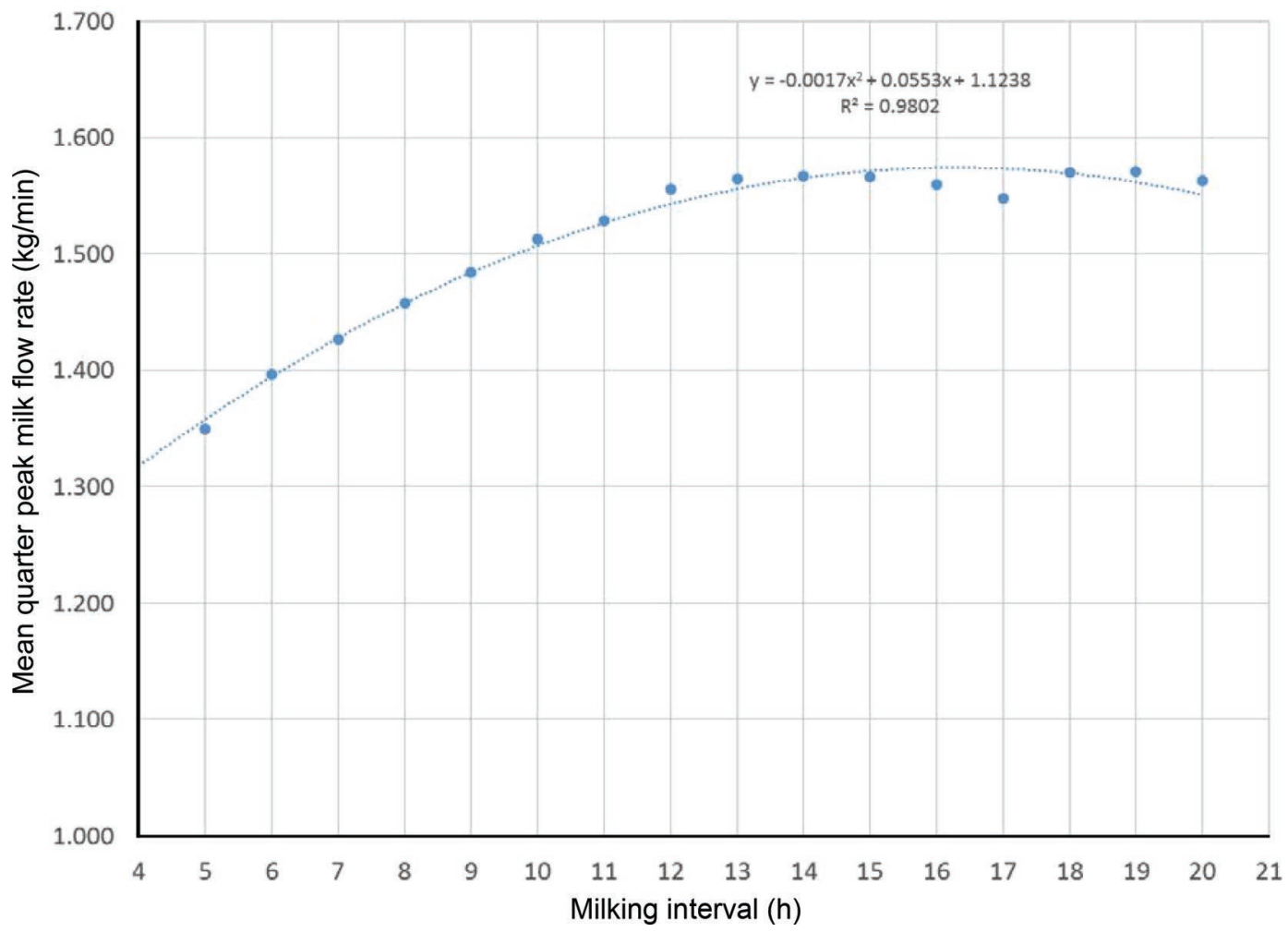

Figure 1. Plot of quarter peak milk flow rate versus milking interval for left front quarter and DIM 10 to 100 (all lactation numbers are included). Color version available online. 


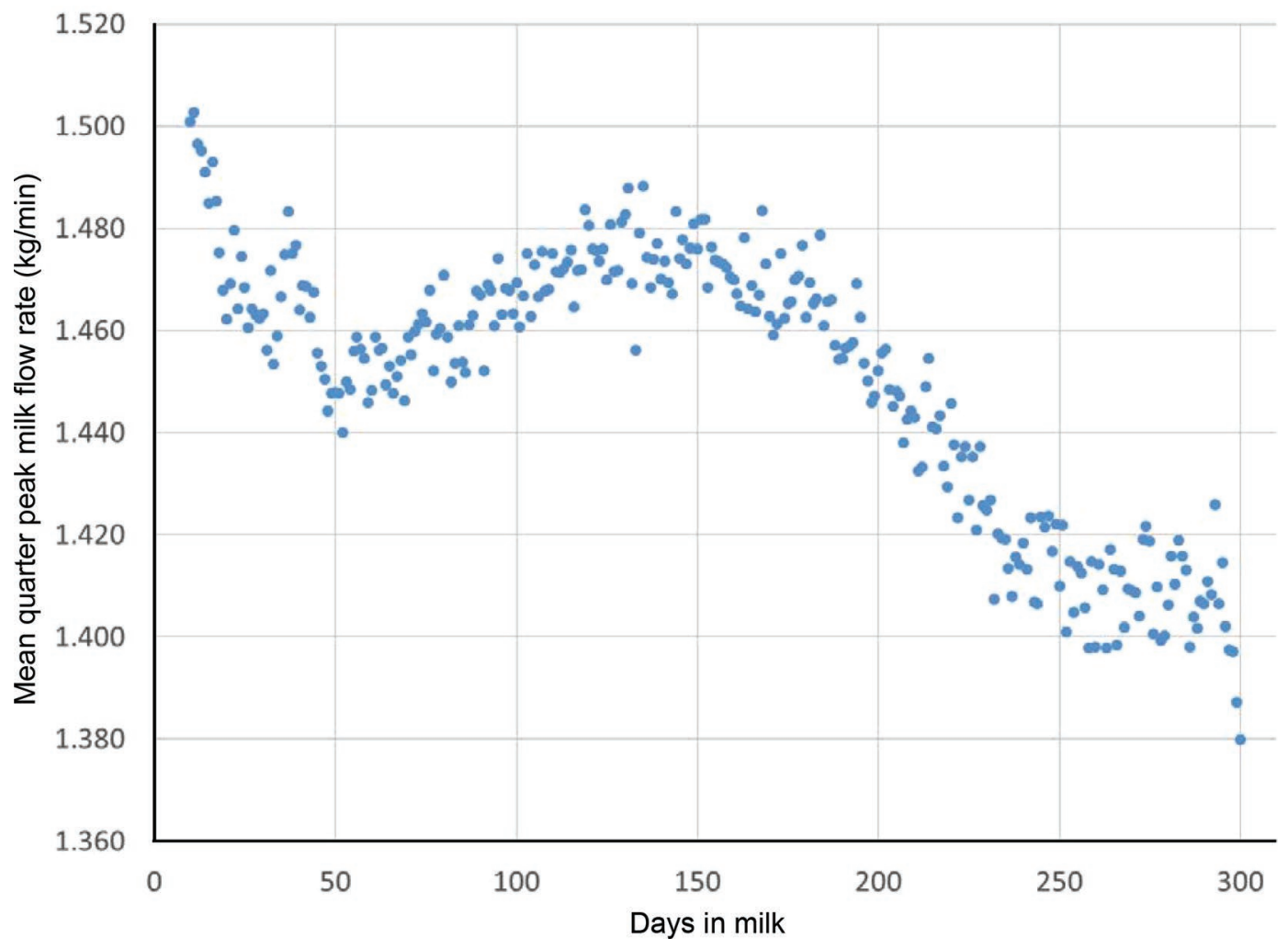

Figure 2. Plot of quarter peak milk flow rate versus DIM for left front quarter and DIM 10 to 300 (all lactation numbers are included). Color version available online.

and Table 6. For all cows in the analysis, front quarters record the highest or second highest contribution to mean udder milk yield (mean within each 10-d DIM window) approximately 24 to $27 \%$ of the time (Table 6). Across all 10-d DIM windows assessed, the mean rank of the front quarters was approximately 1.9; for the rear quarters, the mean rank was approximately 3.0 on a scale of rank 1 (lowest contributor) to 4 (highest contributor). Also based on a 10-d DIM window mean quarter milk yield, quarters were assessed for how often, within an individual cow, they changed rank position at least once during the assessment period. For DIM 10 to 300 , only $14 \%$ of cows had no quarters change rank, whereas $39 \%$ of cows had all 4 quarters change rank at least once in any 10-d DIM window (Table 7). A 0.9-kg change between individual milking QMY was required for quarters to change rank within a milking, which in turn contributed to the 10-d DIM mean QMY used in this calculation. The percentage contribution to 10-d DIM mean udder milk yield regardless of quarter position for DIM windows 10 to 20, 50 to 60 , and 90 to 100 was approximately $30,27,23$, and $20 \%$ for the 4 quarters. For all quarters, the mean SD of percentage contribution to 10-d DIM mean udder milk yield was $6.2 \%$.
The distribution of intra-udder mean QMY standard deviations (SD) for 6 selected 10-d DIM windows, representing a typical lactation length, are shown in Figure 6. Most intra-udder mean QMY SD mean values (one intra-udder mean QMY SD data point per cow per 10-d DIM window representing the mean for all milkings within that window) were $<1 \mathrm{~kg}$. Results from the $t$-test used to assess the difference between mean intra-udder QMY SD between each selected DIM window indicated that all comparisons were statistically different $(P<$ 0.05), but the size of the difference was not considered biologically important. Figure 7 describes MPR rather than milk yield. Mean UPMR was used in preference to udder milk yield because it provides a more accurate estimate of the peak 10-d DIM milk production period for an individual cow, given inconsistent cow MI seen in AMS. The SD of intra-udder mean QMPR is plotted against the peak mean UMPR (peak UMPR for any 10-d DIM window from DIM 10 to 300) in Figure 7. In this linear regression, for each cow, the peak UMPR is displayed along with the corresponding intra-udder QMPR SD for the specific 10-d DIM window associated with the individual peak UMPR. As such, Figure 7 represents a range of DIM windows, typically from 50 to 60 DIM to 110 to 120 DIM, but each cow contributes 


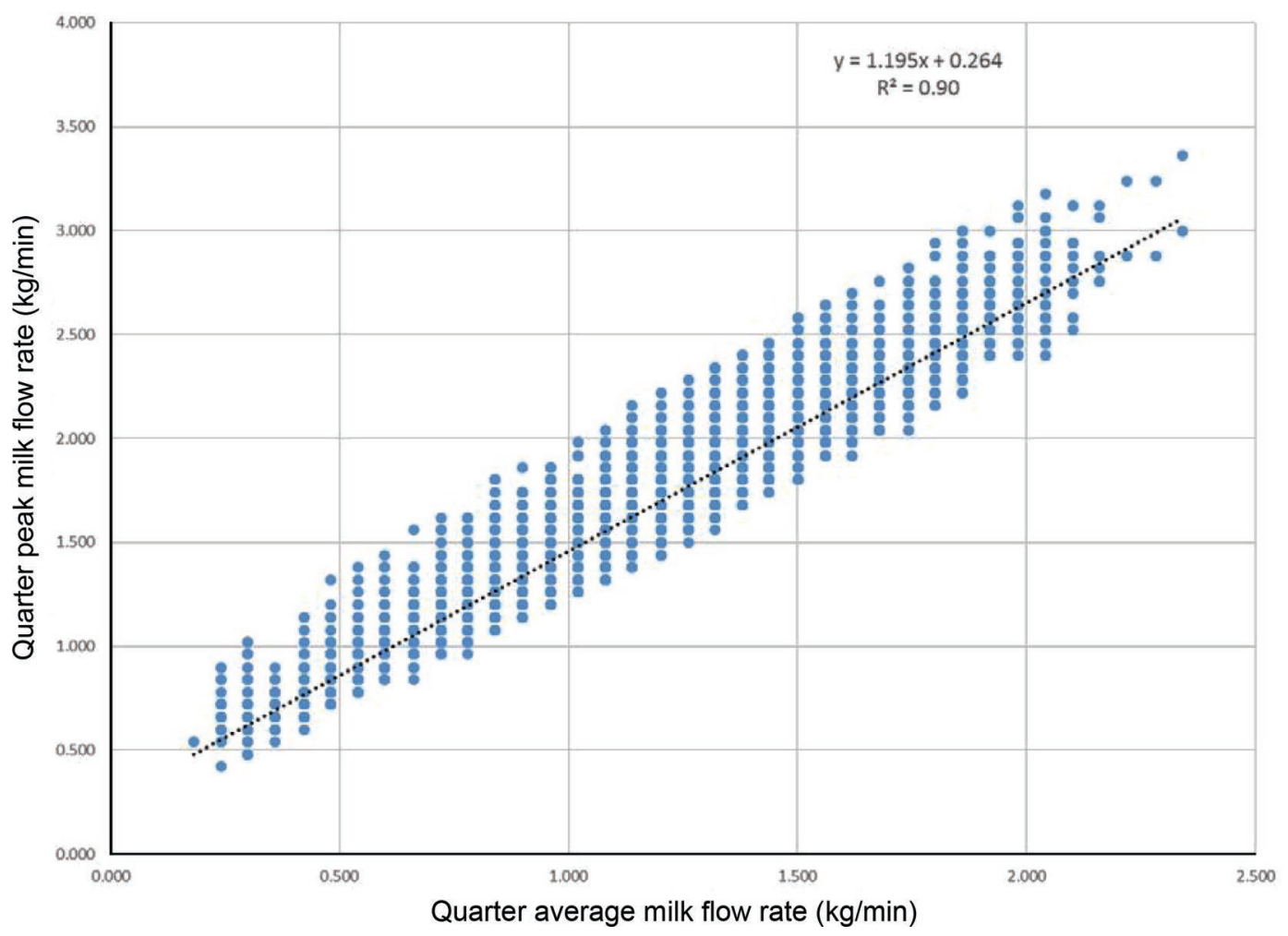

Figure 3. Plot and linear regression of left front quarter peak milk flow rate versus quarter average milk flow rate from DIM 10 to 100 (all lactation numbers are included). Color version available online.

only one data point. The low slope coefficient (0.011) and low $\mathrm{R}^{2}(0.019)$ indicates a poor association between intra-udder QMPR SD and peak UMPR for an individual cow.

\section{DISCUSSION}

We found significant differences in mean QPMF between front and rear quarters from DIM 1 to 300, although the percentage increase in rear quarters was small $(3 \%)$. This result is not in agreement with Tancin et al. (2003), who found similar QPMF between quarters, but supports results from 2 other studies in which higher QPMF was observed in rear quarters than in front quarters (Rothenanger et al., 1995; Tancin et al., 2006). The mean QPMF observed here were greater than the 0.58 to $0.70 \mathrm{~kg} / \mathrm{min}$ previously reported by Rothschild et al. (1980) and $1.03 \mathrm{~kg} / \mathrm{min}$ reported by Ipema and Hogewerf (2008), although the SD of 0.36 $\mathrm{kg} / \mathrm{min}$ observed by Ipema and Hogewerf (2008) was similar to results of the current study. If our observed mean QAMF were aggregated to an approximate mean UAMF $(4.0 \mathrm{~kg} / \mathrm{min})$, it would be a considerably higher UAMF than the 2.51 and $2.50 \mathrm{~kg} / \mathrm{min}$ observed in 2 previous AMS studies (de Koning and Ouweltjes, 2000; Hogeveen et al., 2001).

The association of QPMF and hourly MI has not been previously reported. We found a curvilinear trend for mean QPMF to increase by 1.2 to $2 \%$ with each 1 -h increase in MI up to $\sim 11 \mathrm{~h}$ (Figure 1), with no significant difference among quarter slope linear coefficients. In this herd, mean MI ranged from 8.71 to $9.78 \mathrm{~h}$ for L2+ cows when the lactation was analyzed by early, middle, and late periods (Table 2). This finding aligns with previously reported early- and mid-lactation MI data (Dzidic et al., 2004). In L2+ cows, we detected a significant increase in MI from early to late lactation but no significant trend for L1 cows; this is in general agreement with results from Speroni et al. (2006) and Pettersson et al. (2011), who both observed a smaller increase in L1 MI compared with L2+ MI results. The mean MI (DIM 10-300) for all cows was $8.37 \mathrm{~h}$, which was lower than the $10 \mathrm{~h}$ reported by Gygax et al. (2007) but similar to that reported by Tremblay et al. (2016) in 635 AMS herds. When mean QPMF was regressed against DIM (Figure 2), we detected a decreasing trend, as supported by the $6 \%$ total reduction in QPMF from DIM 10 to 300. Visual assessment 


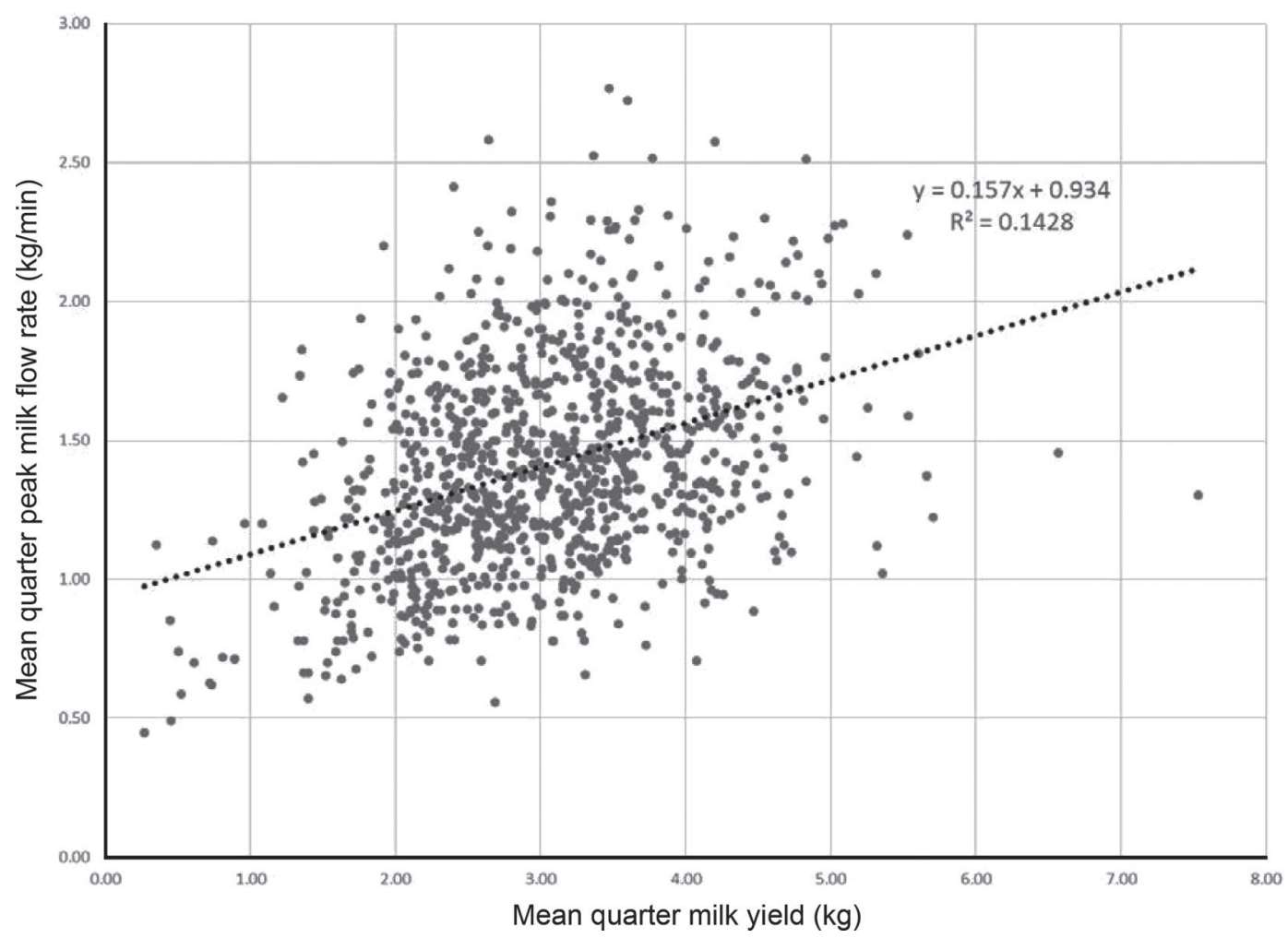

Figure 4. Plot of per cow left front quarter milk yield versus quarter peak milk flow rate for DIM window 50 to 60 (all lactation numbers are included).

of plots for all quarters, together with slope coefficients reported in Table 4, indicates that mean QPMF decreased from DIM 10 to 50, increased between DIM 51 and 150, and then decreased again between DIM 151 and 300. Examination of $\mathrm{R}^{2}$ for all 12 regressions reveal that more of the variability in QPMF data was explained by the linear regression after DIM 51 compared with DIM 1 to 50. The sigmoid-like shape of the plot in Figure 2, as representative of all quarters, has not been reported by other authors. When viewed across all of lactation, the plots are in general agreement with Tancin et al. (2006), who observed a decrease in QPMF only after mo 7 of lactation. Other researchers have reported relatively stable QPMF throughout lactation

Table 6. Distribution of milk yield $\operatorname{ranked}^{1} 3$ or 4 by quarter for all 10-d DIM periods from 10 to 300 DIM (all lactation numbers included)

\begin{tabular}{lc}
\hline Quarter & $\begin{array}{c}\text { Percent of all 10-DIM } \\
\text { periods ranked 3 or 4 }\end{array}$ \\
\hline Left front & 24.3 \\
Right front & 27.5 \\
Left rear & 75.1 \\
Right rear & 73.1 \\
\hline
\end{tabular}

${ }^{1}$ Rank is 1 (lowest) to 4 (highest) milk yield based on a 10-d DIM window.

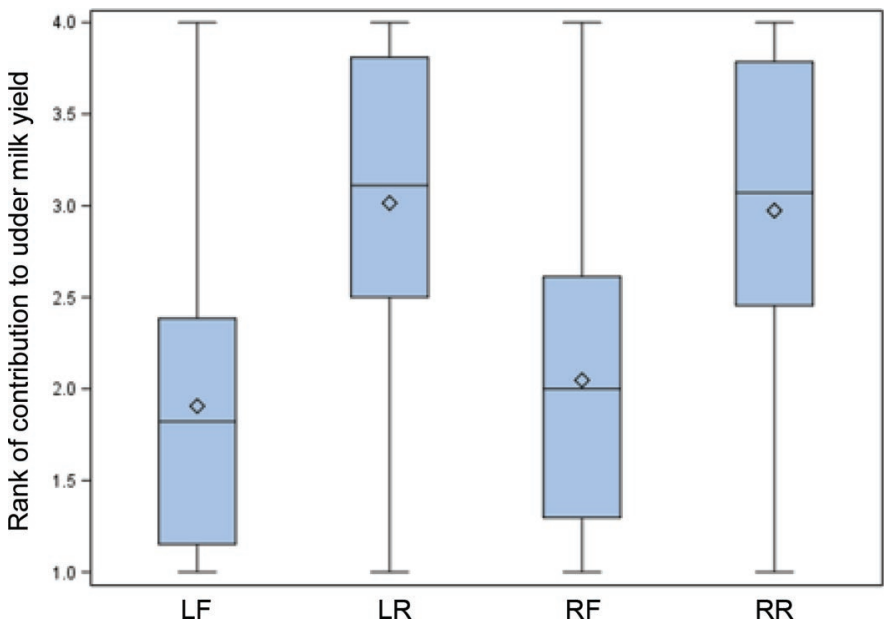

Figure 5. Distribution of quarter milk yield rank based on 10-d DIM windows from 10 to 300 DIM. Lowest ranked contribution to udder milk yield (1) through to highest rank (4) for quarters left front $(\mathrm{LF})$, left rear (LR), right front (RF), and right rear (RR). All lactation numbers are included. Bottom and top edges of box plot are located at the sample 25th and 75th percentiles. The center horizontal line indicates the sample median. The diamond indicates the sample mean. Central vertical lines extend from the box as far as the data extend to a limit of 1.5 interquartile ranges. Color version available online. 
Table 7. Descriptive data on change in within cow, quarter (Q) milk yield rank $^{1}$ for DIM 10 to 300 (all lactation numbers included)

\begin{tabular}{lc}
\hline Change in Q milk yield rank & No. (\%) of cows \\
\hline Cows analyzed & 1,488 \\
All 4 Q change rank & $585(39.3)$ \\
3 Q change rank & $300(20.2)$ \\
2 Q change rank & $396(26.6)$ \\
No Q change rank & $207(13.9)$ \\
\hline
\end{tabular}

${ }^{1}$ Change in rank is based on 2 or more quarters changing rank at least once based on quarter milk yield rank calculated in each 10-d DIM window. Rank is 1 (lowest) through to 4 (highest) milk yield based on a 10-d DIM window.

(Rothenanger et al., 1995; Halley et al., 2001; Ipema and Hogewerf, 2008). Overall, our data agree with the high repeatability previously observed with QPMF compared from milking to milking, where the standard error of measurement (designated "w" or Dahlberg's formula) was 0.9 (Rothenanger et al., 1995).

In this study, we performed linear regression to quantify the association of QPMF and QAMF in addition to UPMF and UAMF and obtained similar results for
$\mathrm{R}^{2}$ values. A strong association was found between mean QPMF and mean QAMF, with $\mathrm{R}^{2}$ of all regressions being between 0.90 and 0.92 . This agrees with previous findings in small research herds, where good associations were described between these 2 variables at both the cow and quarter levels (Rothenanger et al., 1995; Weiss et al., 2004). No other researchers have reported a significant increase in the regression slope coefficient of front quarters compared with rear quarters as observed in this study. This large data set showed only a weak association between mean QPMF and mean QMY (Figure 4), as indicated by the low mean $\mathrm{R}^{2}(0.172)$. Hence, QMY is a poor indicator of QPMF in all DIM windows assessed (50 to 60, 100 to 110, 150 to 160,200 to 210,250 to 260). This observation is supported by the results of a small study with 38 cows that found no relationship between UPMF and udder milk yield (Weiss et al., 2004) and another 38-cow experiment where peak milk flow rate was classified into low, medium, and high levels and milk yield was not associated with peak milk flow rate at either the quarter or cow level (Tancin et al., 2006). A larger

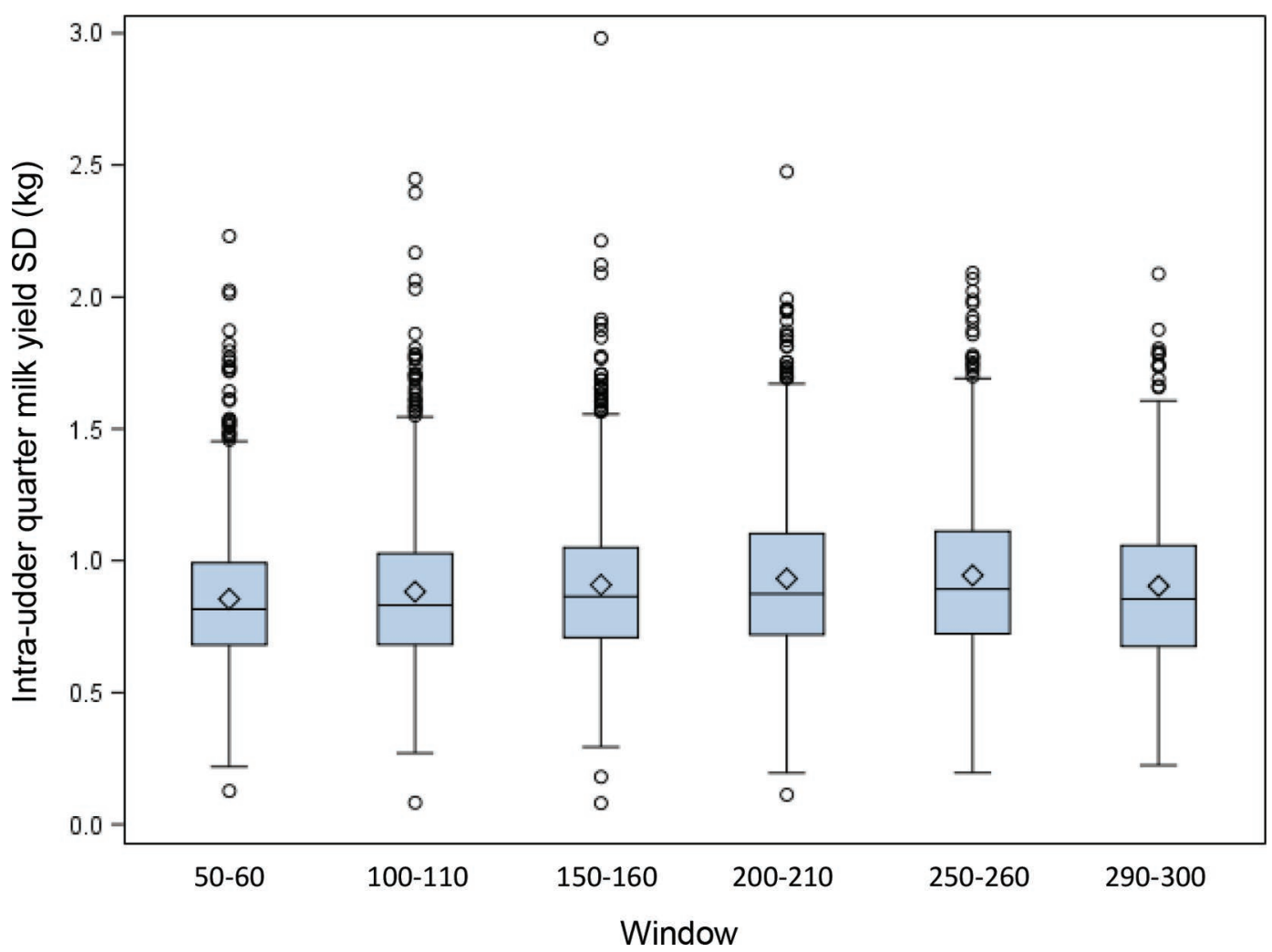

Figure 6. Distribution of intra-udder quarter milk yield standard deviations (kg) for DIM windows 50 to 60,100 to 110,150 to 160,200 to 210, 250 to 260, and 290 to 300. All lactation numbers are included. Bottom and top edges of box plot are located at the sample 25th and 75th percentiles. The center horizontal line indicates the sample median. The diamond indicates the sample mean. Central vertical lines extend from the box as far as the data extend to a limit of 1.5 interquartile ranges. Any data value more extreme than this is marked with a circle to a limit of 3 interquartile ranges. Color version available online. 


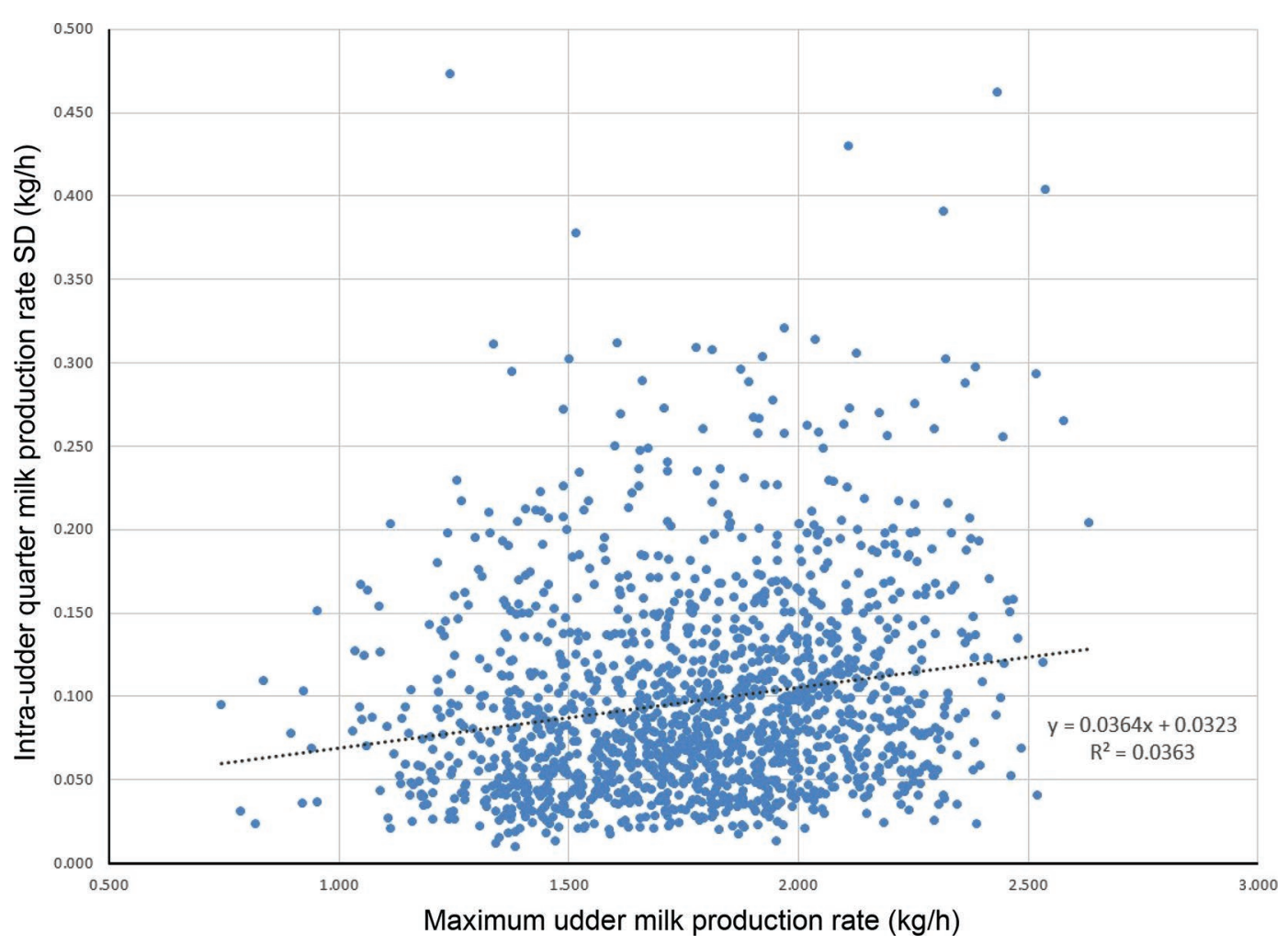

Figure 7. Plot of per cow intra-udder mean quarter milk production rate standard deviations $(\mathrm{kg} / \mathrm{h})$ versus mean maximum udder milk yield rate within a 10-d DIM window for DIM 10 to 300 (all lactation numbers included). Color version available online.

observational study with 1,024 cows reported that $12 \%$ of the variation in UPMF was due to udder milk yield (Halley et al., 2001).

These results can be used to better understand AMS efficiency. Increasing both UAMF and UPMF has a positive effect on the number of milkings per day in AMS (de Koning and Ouweltjes, 2000; Castro et al., 2012) as the preparation time before and after teatcup attachment is relatively fixed and a considerable proportion of total AMS time per milking (André at al., 2010). It is estimated that between 75 (Hogewerf and Ipema, 2000) and 80\% (Ipema and Hogewerf, 2008) of QMY is harvested during the peak milk flow period, so understanding the cow factors that might be associated with QPMF is relevant to the efficiency of milk harvesting. In this data set, we observed a clear association between QPMF and MI and between QPMF and QAMF, only a moderate association between QPMF and DIM, and a weak association between QPMF and QMY. Knowledge of QMY, or udder milk yield, is very limited in its predictive ability for QPMF. Using QMT to determine teatcup attachment order shows promise for improving the rate of milk harvested per AMS, given we determined that suboptimal attachment order harvested only $58 \%$ of milk per unit AMS time com- pared with an optimal attachment order. This clearer understanding of associations of cow-level factors with QPMF or UPMF can be used to develop better AMS unit in-use time budgets where teatcup attachment is in a fixed order. Alternatively, if teatcup attachment order can be modified, QMT would be a preferred parameter to QMY for determining attachment order. Because of the very tight association between QPMF and QAMF, where pre-attachment teat preparation is highly consistent as in AMS, cow-level factors associated with QPMF will be of similar nature to those associated with QAMF. Along with QPMF, QAMF is a useful indicator of milking management.

The approach to assessing QMY variability in this research was to use the ranking of percentage contribution to udder milk yield as a primary metric. Although we did calculate the within-udder CV of QMY, we contend that a description of percentage contribution to udder milk yield is a more intuitive measurement to understand QMY variability in a large data set. We elected to use milk yield measured at each milking, rather than an estimate of daily milk yield, because of previously described problems with accurately estimating daily milk yield parameters in AMS (Nielsen et al., 2010). Figure 5 and Table 6 illustrate that, when 
assessed over the lactation, rear quarter contribution to udder milk yield does not always exceed that of front quarters. In approximately 24 to $27 \%$ of $10-\mathrm{d}$ DIM windows, the front quarters make the highest or second highest contribution to udder milk yield. The front quarters of individual cows in this study herd contributed approximately $43 \%$ of total milk yield, which is greater than that reported in a multi-year study (40.6\%; Rothschild et al., 1980), although detail on how many milkings were assessed in the 198 cows in the Rothschild et al. (1980) study is lacking. Hogewerf and Ipema (2000) measured the contribution of front quarters to be $44 \%$ of udder milk yield but this was limited to only 12 study cows over $6 \mathrm{~d}$. A 5 -d study with 105 cows observed that milk production rate was $33 \%$ greater in rear quarters than in front quarters over the study period (Kohler and Kaufmann, 2003). The results of these last 2 studies compared with our results indicate that measuring QMY percentage contribution over an extended period provides a more complete picture of how individual quarters contribute to udder milk yield in a large herd. Tancin et al. (2006) reported the contribution of front quarters to udder milk yield to be $44.1 \%$ in 38 cows over 10 mo but did not describe any analysis by discrete DIM windows within the study period. No other authors have described the rank of percentage quarter contribution to udder milk yield regardless of quarter position, mean SD of percentage quarter contribution, or how quarter rank changes over a lactation (Table 7). Our analysis demonstrates that relatively few cows (10\%) have quarters that never change contribution rank over a lactation, whereas the contribution of the highest ranked quarter to the lowest ranked quarter, irrespective of quarter physical location and over time, is relatively stable. This is supported by analysis in Figure 6, which indicated a small but significant change in 10-d DIM intra-udder QMY SD from DIM 50 to 300. The range of CV for QMY observed in our data set ( 35 to $42 \%$ ) was higher than the 19 to $23 \%$ observed in 858 cows (control group, uninfected) reported over a 13-wk analysis window by Fogsgaard et al. (2015) or the $7 \%$ observed over 3 wk in 10 cows by Forsbäck et al. (2010). Our assumption is that the increase in within-cow QMY variability determined in our study was a result of having a larger population of cows observed for a longer period. Indeed, in this study, $39 \%$ of cows had all 4 quarters change contribution rank at least once during any 10-d window within the analysis period. The mean SD of percentage quarter contribution was approximately $6 \%$, meaning that, for example, with a mean rear quarter percentage contribution of approximately $28 \%$, the SD represents almost $22 \%$ of the mean quarter contribution.
The final question posed in this research concerned peak UMPR during a lactation and whether this was associated with low or high QMPR variability. Quarter milk production rate has been examined in a past study but only through a comparison of front and rear quarters (Kohler and Kaufmann, 2003). Milk production rate, as a function of a.m. hours, p.m. hours, and MI, has been described at the cow level (Quist et al., 2008) in addition to AMS-specific studies where UMPR was found to generally increase as MI decreased for a given DIM window (Hogeveen et al., 2001; Bach and Busto, 2005). However, there are no previous reports on the association of UMPR and QMPR variability. The $\mathrm{R}^{2}$ value for the regression described in Figure 7 was $<0.04$, indicating that the linear regression of peak UMPR versus QMPR SD explained less than $4 \%$ of the variation in the observed data. From this result, we can conclude that cows with higher peak UMPR do not tend to have either high or low QMPR variability, because the association between these 2 variables was weak.

\section{CONCLUSIONS}

This observational study showed that, in a large study herd, QPMF was associated with the cow-level factors MI and DIM. Peak milk flow rate was strongly associated with average milk flow rate (quarter and udder level) in a linear relationship, with MI in a curvilinear fashion, but with DIM in a sigmoid-like pattern. Knowledge of QMY is not useful in predicting QPMF. The contribution of an individual quarter to udder milk yield is highly variable across a lactation, as indicated by the change in contribution rank. In at least $24 \%$ of any lactation, front quarters are the highest or second highest quarter for milk contribution at some point during a lactation. Knowledge of QMT appears useful in predicting teatcup attachment order to optimize milk harvested per unit AMS time. Although caution needs to be expressed around the generalizability of any observational study, the size of this study population and the period over which data were gathered confers robustness to the analysis.

\section{ACKNOWLEDGMENTS}

This research, conducted by the University of Wisconsin-Madison, is supported by Avon Dairy Solutions (Melksham, UK) and Dairy Australia (Melbourne, Australia). The researchers express their gratitude to the owners and staff at Mason Dixon Dairies (Pennsylvania) for their assistance with this study. 


\section{REFERENCES}

André, G., P. B. M. Berentsen, B. Engel, C. de Koning, and A. Lansink. 2010. Increasing the revenues from automatic milking by using individual variation in milking characteristics. J. Dairy Sci. 93:942-953.

Bach, A., and I. Busto. 2005. Effects on milk yield of milking interval regularity and teat cup attachment failures with robotic milking systems. J. Dairy Res. 72:101-106.

Castro, A., J. M. Pereira, C. Amiama, and J. Bueno. 2012. Estimating efficiency in automatic milking systems. J. Dairy Sci. 95:929-936.

de Koning, K., and W. Ouweltjes. 2000. Maximising the milking capacity of an automatic milking system. Pages 38-46 in Robotic Milking. Wageningen Academic Publishers, Wageningen, the Netherlands.

Dzidic, A., D. Weiss, and R. M. Bruckmaier. 2004. Oxytocin release, milk ejection and milking characteristics in a single stall automatic milking system. Livest. Prod. Sci. 86:61-68.

Fogsgaard, K. K., P. Lovendahl, T. W. Bennedsgaard, and S. Ostergaard. 2015. Changes in milk yield, lactate dehydrogenase, milking frequency, and interquarter yield ratio persist for up to 8 weeks after antibiotic treatment of mastitis. J. Dairy Sci. 98:7686-7698.

Forsbäck, L., H. Lindmark-Mansson, A. Andren, M. Akerstedt, L. Andree, and K. Svennersten-Sjaunja. 2010. Day-to-day variation in milk yield and milk composition at the udder-quarter level. J. Dairy Sci. 93:3569-3577.

Gygax, L., I. Neuffer, C. Kaufmann, R. Hauser, and B. Wechsler. 2007. Comparison of functional aspects in two automatic milking systems and auto-tandem milking parlors. J. Dairy Sci. 90:4265-4274.

Hallen Sandgren, C., and U. Emanuelson. 2017. Is there an ideal automatic milking system cow and is she different from an ideal parlormilked cow? Pages 61-68 in Proc. 56th Natl. Mastitis Counc. Ann. Mtg., St. Pete Beach, FL. Natl. Mastitis Counc. Inc., New Prague, MN.

Halley, B., J. Barlow, A. Bramley, J. Hillerton, D. Howell, and J. W Pankey. 2001. Observational studies on the association between peak milk flow rate and somatic cell count. Pages 179-180 in Proc. 40th Natl. Mastitis Counc. Ann. Mtg., Reno, NV. Natl. Mastitis Counc. Inc., Madison, WI.

Hogeveen, H., W. Ouweltjes, C. de Koning, and K. Stelwagen. 2001. Milking interval, milk production and milk flow-rate in an automatic milking system. Livest. Prod. Sci. 72:157-167.

Hogewerf, P. H., and A. H. Ipema. 2000. Analysis of differences in yield and milk flow properties between front and rear quarters. Pages 60-61 in Robotic Milking. Wageningen Academic Publishers, Wageningen, the Netherlands.

Ipema, A. H., and P. H. Hogewerf. 2008. Quarter-controlled milking in dairy cows. Comput. Electron. Agric. 62:59-66.
Kohler, S. D., and O. Kaufmann. 2003. Quarter-related measurements of milking and milk parameters in an AMS-herd. Milchwissenschaft 58:3-6.

Nielsen, P. P., G. Pettersson, K. M. Svennersten-Sjaunja, and L. Norell. 2010. Technical note: Variation in daily milk yield calculations for dairy cows milked in an automatic milking system. J. Dairy Sci. 93:1069-1073.

Pettersson, G., K. Svennersten-Sjaunja, and C. H. Knight. 2011. Relationships between milking frequency, lactation persistency and milk yield in Swedish Red heifers and cows milked in a voluntary attendance automatic milking system. J. Dairy Res. 78:379-384.

Quist, M. A., S. J. LeBlanc, K. J. Hand, D. Lazenby, F. Miglior, and D. F. Kelton. 2008. Milking-to-milking variability for milk yield, fat and protein percentage, and somatic cell count. J. Dairy Sci. 91:3412-3423.

Rothenanger, E., R. M. Bruckmaier, and J. W. Blum. 1995. Association and dissociation of single quarter and total milk flow in dairy cows - Effects of milking with and without pre-stimulation. Milchwissenschaft 50:63-67.

Rothschild, M. F., G. W. Bodoh, R. E. Pearson, and R. H. Miller. 1980. Sources of variation in quarter milk flow measures. J. Dairy Sci. 63:1138-1144.

Sonck, B. R., and H. W. J. Donkers. 1995. The milking capacity of a milking robot. J. Agric. Eng. Res. 62:25-37.

Speroni, M., G. Pirlo, and S. Lolli. 2006. Effect of automatic milking systems on milk yield in a hot environment. J. Dairy Sci 89:4687-4693.

Tancin, V., A. H. Ipema, D. Peskovicova, P. H. Hogewerf, and J. Macuhova. 2003. Quarter milk flow patterns in dairy cows: factors involved and repeatability. Vet. Med. (Praha) 48:275-282.

Tancin, V., B. Ipema, P. Hogewerf, and J. Macuhova. 2006. Sources of variation in milk flow characteristics at udder and quarter levels. J. Dairy Sci. 89:978-988.

Tremblay, M., J. P. Hess, B. M. Christenson, K. K. McIntyre, B Smink, A. J. van der Kamp, L. G. de Jong, and D. Dopfer. 2016 Factors associated with increased milk production for automatic milking systems. J. Dairy Sci. 99:3824-3837.

Wall, E. H., and T. B. McFadden. 2012. Triennial Lactation Symposium: A local affair: How the mammary gland adapts to changes in milking frequency. J. Anim. Sci. 90:1695-1707.

Weaver, S. R., and L. L. Hernandez. 2016. Autocrine-paracrine regulation of the mammary gland. J. Dairy Sci. 99:842-853.

Weiss, D., M. Weinfurtner, and R. M. Bruckmaier. 2004. Teat anatomy and its relationship with quarter and udder milk flow characteristics in dairy cows. J. Dairy Sci. 87:3280-3289.

Wellnitz, O., R. M. Bruckmaier, and J. W. Blum. 1999. Milk ejection and milk removal of single quarters in high yielding dairy cows. Milchwissenschaft 54:303-306. 